\title{
Sg17-1-4, a Novel Isocoumarin from a Marine Fungus Alternaria tenuis Sg17-1
}

\author{
Yong-Fu Huang, Lin-Hao Li, Li Tian, Li Qiao, Hui-Ming Hua, Yue-Hu Pei
}

Received: March 4, 2006 / Accepted: May 19, 2006

(C) Japan Antibiotics Research Association

\begin{abstract}
One novel isocoumarin, named Sg17-1-4, along with two known isocoumarins AI-77-B and AI-77-F were obtained from a marine fungus Alternaria tenuis Sg17-1. Their structures were elucidated based on detailed NMR analysis. The cytotoxicities of these compounds were evaluated in vitro.
\end{abstract}

Keywords marine fungus, isocoumarin, cytotoxicity

Isocoumarins such as the amicoumacins, the AI-77 series of compounds and the xenocoumacins have displayed antibacterial, antitumor and potent antiulcer activities [1 3]. They have been isolated from bacteria. The AI-77 series of compounds were all derived from culture broths of the genus Bacillus. In the course of screening bioactive natural compounds from marine microorganisms, three compounds, AI-77-B (1), AI-77-F (2) and Sg17-1-4 (3) were isolated from the culture broth of a marine fungus Alternaria tenuis $\mathrm{Sg} 17-1$. Compound $\mathbf{3}$ is a novel isocoumarin, which possesses an unusual 7-number ring in its side chain. This is the first time compounds of this type have been isolated from a fungus. The cytotoxicities of these compounds have been tested using A375 S2 and HeLa cells in vitro. Here, we report the isolation, structural elucidation and bioactivities of these compounds.

The fungal strain was isolated from a marine alga collected in Zhoushan Island in 2003 and identified as
Alternaria tenuis by Prof. Li Tian. A voucher specimen (No. CAAN034015) is deposited in Key laboratory of Marine Biology of State Oceanography Administration, China. The strain was incubated in forty $500-\mathrm{ml}$ flasks each containing $100 \mathrm{ml}$ of medium for 12 days at $25^{\circ} \mathrm{C}$ on a rotary shaker $(150 \mathrm{rpm})$. The culture medium contained corn steep liquor $200 \mathrm{ml}$, peptone $2.0 \mathrm{~g}$, yeast powder $1.0 \mathrm{~g}$, dextrose $10 \mathrm{~g}, \mathrm{NaCl} 17 \mathrm{~g}, \mathrm{MgCl}_{2} \cdot 6 \mathrm{H}_{2} \mathrm{O} 1.3 \mathrm{~g}, \mathrm{KCl} 0.1 \mathrm{~g}$ and $\mathrm{FePO}_{4} 0.01 \mathrm{~g}$ in distilled water of $1000 \mathrm{ml}$. The harvested broth (40 liters) was centrifugated to separate the mycelial mass from the aqueous layer. The aqueous layer was extracted with 1-butanol exhaustively. The organic layer was evaporated under reduced pressure to obtain a crude residue. The residue $(20 \mathrm{~g})$ was chromatographed on a silica gel column using a gradient of methanol in chloroform. Fractions eluted with methanol - chloroform $10: 100$ were combined to be and further purified over on a Sephadex LH-20 column (Pharmadex, $\mathrm{CHCl}_{3} / \mathrm{MeOH} 1: 1$ ). The final purification was carried on reversed-phase silica gel (Chromatorex $\left.\mathrm{C}_{18}, \mathrm{MeOH} / \mathrm{H}_{2} \mathrm{O} 1: 1\right)$ to give $\mathbf{1}(10 \mathrm{mg}), 2$ $(12 \mathrm{mg})$ and $3(7 \mathrm{mg})$ respectively.

Compounds $\mathbf{1}$ and $\mathbf{2}$ were identified as AI-77-B and AI77-F, respectively, by comparison with the literature [4] and on the basis of various spectroscopic analyses.

Compound 3, an amorphous white powder $(\mathrm{MeOH})$, gave a positive color reaction with ninhydrin and $\mathrm{FeCl}_{3}$ reagent and a negative color reaction with bromocresol green reagent. The $\mathrm{mp}$ was $147 \sim 149^{\circ} \mathrm{C}$ and $[\alpha]_{\mathrm{D}}^{20}-110^{\circ}(c$ $0.1, \mathrm{MeOH})$. Its molecular weight was found to be 494 by
Y.-H. Pei (Corresponding author), Y.-F. Huang, L. Qiao, H.-M. Hua: School of Traditional Chinese Materia Medica, Shenyang Pharmaceutical University, Shenyang 110016, China,

E-mail: peiyueh@vip.163.com
L.-H. Li: China-Japan Research Institute of Medical and Pharmaceutical Sciences, Shenyang Pharmaceutical University, Shenyang 110016, China

L. Tian: First Institute of Oceanography, State Oceanography Administration, Qingdao 266061, China 
Table $1{ }^{1} \mathrm{H}(600 \mathrm{MHz})$ and ${ }^{13} \mathrm{C}(150 \mathrm{MHz}) \mathrm{NMR}$ data of sg17-1-4, b

\begin{tabular}{|c|c|c|c|c|c|}
\hline${ }^{13} \mathrm{C}$ shift & ${ }^{1} \mathrm{H}$ shift & Assignment & ${ }^{13} \mathrm{C}$ shift & ${ }^{1} \mathrm{H}$ shift & Assignment \\
\hline 173.3 & & $12^{\prime}$ & 48.7 & $2.91(q, 6.4)$ & $15^{\prime}$ \\
\hline 171.8 & & $7^{\prime}$ & 48.1 & $4.22(\mathrm{~m})$ & $5^{\prime}$ \\
\hline 169.3 & & 1 & 48.0 & $3.19(\mathrm{~m})$ & $10^{\prime}$ \\
\hline 160.9 & & 8 & 39.0 & $1.33(\mathrm{~m}), 1.66(\mathrm{~m})$ & $4^{\prime}$ \\
\hline 140.9 & & 10 & 29.1 & $2.82(\mathrm{~m}), 3.10(\mathrm{~m})$ & 4 \\
\hline 136.3 & $7.48(t, 7.9)$ & 6 & 28.2 & $2.21(\mathrm{~m}), 2.52(\mathrm{~m})$ & $11^{\prime}$ \\
\hline 118.8 & $6.83(d, 7.9)$ & 5 & 24.6 & $0.93(s)$ & $18^{\prime}$ \\
\hline 115.2 & $6.84(d, 7.9)$ & 7 & 24.2 & $1.66(\mathrm{~m})$ & $3^{\prime}$ \\
\hline 108.4 & & 9 & 23.4 & $0.88(d, 6.3)$ & $2^{\prime}$ \\
\hline 94.6 & & $14^{\prime}$ & 21.6 & $0.86(d, 6.3)$ & $1^{\prime}$ \\
\hline 81.2 & 4.70 (ddd, 12.7, 3.4, 2.9) & 3 & 15.3 & $0.93(d, 6.4)$ & $17^{\prime}$ \\
\hline 70.1 & $3.81(d, 8.9)$ & $8^{\prime}$ & & 7.97 (s) & $6^{\prime}$ \\
\hline 68.5 & $4.26(\mathrm{dd}, 8.9,3.1)$ & $9^{\prime}$ & & & \\
\hline
\end{tabular}

${ }^{a}$ Recorded in DMSO- $d_{6}$, coupling constant $(\mathrm{Hz})$.

${ }^{\mathrm{b}}$ Assignments are based on $\mathrm{HMOC}, \mathrm{HMBC}, \mathrm{HHCOSY}, \mathrm{NOESY}$ data.
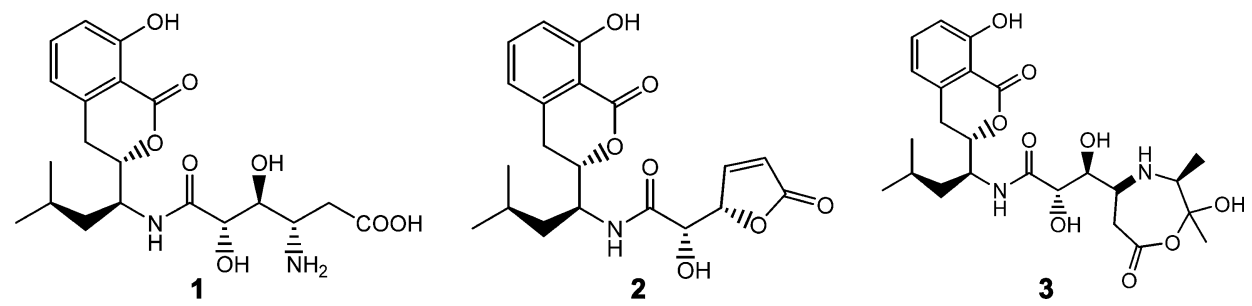

Fig. 1 Structures of Al-77-B (1), Al-77-F (2) and sg17-1-4 (3).

ESI-MS that showed a protonated molecular ion at $\mathrm{m} / \mathrm{z}$ $495.1(\mathrm{M}+\mathrm{H})^{+}$. The molecular formula was established as $\mathrm{C}_{24} \mathrm{H}_{34} \mathrm{O}_{9} \mathrm{~N}_{2}$ by HR-SIMS $\left[m / z 495.2334(\mathrm{M}+\mathrm{H})^{+}\right.$], which suggested that 3 had 9 units of unsaturation. The UV $(\mathrm{MeOH})$ spectrum displayed bands at $314 \mathrm{~nm}, 246 \mathrm{~nm}$ and $209 \mathrm{~nm}$, which was similar to those of $\mathbf{1}$ and $\mathbf{2}$. The IR spectrum, $v_{\max }(\mathrm{KBr}) \mathrm{cm}^{-1}: 3392,2930,1790,1672,1570$ suggested the presence of a phenolic hydroxyl, an amide group and a saturated ester carbonyl. All these findings above suggested that $\mathbf{3}$ contained a chromophore similar to 3,4-dihydro-8-hydroxyisocoumarin in its structure. The NMR spectra of 3 (Table 1) were similar to those of compound 1. Analysis of the 1D and 2D (HMQC, HMBC, HHCOSY and NOESY) NMR spectra of 3 (Fig. 2), suggested a partial structure A as seen in compound 1 (Fig. 1). In addition to the signals for structure $A$, protons from two methyl at $\delta 0.93\left(3 \mathrm{H}, \mathrm{s}, \mathrm{H}-18^{\prime}\right)$ and $0.91(3 \mathrm{H}, \mathrm{d}$, $\left.J=6.4 \mathrm{~Hz}, \mathrm{H}-17^{\prime}\right)$ and one methine proton at $\delta 2.91(1 \mathrm{H}, \mathrm{q}$, $\left.J=6.4 \mathrm{~Hz}, \mathrm{H}-15^{\prime}\right)$ can be observed in the ${ }^{1} \mathrm{H}$ NMR spectrum of 3. One quaternary carbon at $\delta 94.6\left(\mathrm{C}-14^{\prime}\right)$, one tertiary carbon at $\delta 48.7\left(\mathrm{C}-15^{\prime}\right)$ and two primary carbons at $\delta 24.6\left(\mathrm{C}-18^{\prime}\right), 15.3\left(\mathrm{C}-17^{\prime}\right)$ can be observed in the ${ }^{13} \mathrm{C}$ NMR spectrum of 3 . In the HMBC spectrum the proton signal at $\delta 0.93\left(3 \mathrm{H}, \mathrm{s}, \mathrm{H}-18^{\prime}\right)$ and $0.91(3 \mathrm{H}, \mathrm{d}$, $\left.J=6.4 \mathrm{~Hz}, \mathrm{H}-17^{\prime}\right)$ showed $\mathrm{C}-\mathrm{H}$ long-range correlations with $\mathrm{C}-15^{\prime}\left(\delta\right.$ 48.7) and $\mathrm{C}-14^{\prime}$ ( $\delta$ 94.6), respectively. By analysis of the 2D NMR and chemical shift values of these data, another partial structure B can be obtained. By further analysis of the HMBC data of $\mathbf{3}$, the correlation between the proton at $\delta 3.19\left(\mathrm{H}-10^{\prime}\right)$ in structure A and the carbon at $\delta 48.7\left(\mathrm{C}-15^{\prime}\right)$ in structure $\mathrm{B}$ can be observed. Therefore, considering the degrees of unsaturation and 2D NMR of $\mathbf{3}$, we conclude that the new isocoumarin Sg17-1-4 has the planar structure C. Compound $\mathbf{3}$ was obtained from the same source as compounds $\mathbf{1}$ and $\mathbf{2}$, so the absolute configurations at $\mathrm{C} 3, \mathrm{C}^{\prime}, \mathrm{C} 8^{\prime}, \mathrm{C} 9^{\prime}, \mathrm{C} 10^{\prime}$ should be same as those of $\mathbf{1}$ and $\mathbf{2}$. The $\mathrm{CD}$ spectrum of $\mathbf{3}\left(\Delta \varepsilon_{326}-0.35\right.$, $\left.\Delta \varepsilon_{306}-0.48, \Delta \varepsilon_{258}-4.2, \mathrm{MeOH}\right)$ was identical with those of $\mathbf{1}$ and $\mathbf{2}$, which also confirmed this conclusion. The NOE between $\mathrm{H}-10^{\prime}$ and $\mathrm{H}-15^{\prime}$ was obviously observed, which indicated $\mathrm{C}-15^{\prime}$ had an $S$-configuration. As a hemiacetal carbon, the configuration at $\mathrm{C} 14$ ' couldn't be defined. 
<smiles>COC(=O)CC(NCS)C(O)C(O)C(=O)NC(CC(C)C)C1Cc2cccc(O)c2C(=O)O1</smiles>

Fig. 2 The selective 2D NMR correlations of $\mathbf{3}$.

$-{ }^{1} \mathrm{H}^{-}{ }^{1} \mathrm{H}$ COSY $\longrightarrow \mathrm{HMBC}$.

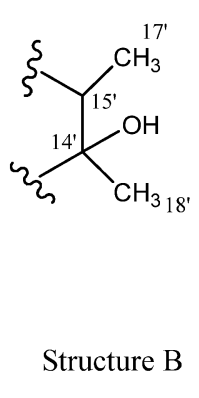

Structure B

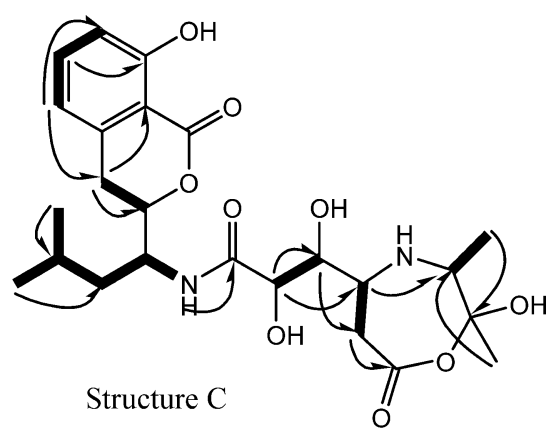

Finally, the structure of $\mathbf{3}$ is identified as Fig. 1 shows.

The cytotoxicities in vitro against human malignant A375-S2 and human cervicial cancer Hela cells were measured with the MTT assay [5]. Compound 1 exhibited the strongest activity with $\mathrm{IC}_{50}$ values of 0.1 and $0.02 \mathrm{mM}$, respectively. The values of 3 were 0.3 and $0.05 \mathrm{mM}$. Compound 2 showed only weak activity to Hela cells with an $\mathrm{IC}_{50}$ value of $0.4 \mathrm{mM}$.

Acknowledgments This work was supported by $863 \mathrm{Hi}$-Tech Research and Development Program of China (Grant No. 2001AA624020) and the Fund for the 973-project from Ministry of Science and Technology (Grant No. G1998051100), China.

\section{References}

1. Shimojima Y, Hayashi H, Ooka T, Shibukawa M. Studies on
AI-77s, microbial products with pharmacological activities. Part I. Production, isolation and pharmacological studies of AI-77s. Agric Biol Chem 46: 1823-1829 (1982)

2. Itoh J, Omoto S, Shomura T, Nishizawa N, Miyado S, Yuda Y, Shibata U, Inouye S. Physicochemical properties and biological activities of amicoumacins produced by Bacillus pumilus. Agric Biol Chem 46: 1255-1259 (1982)

3. Mcinerney BV, Taylor WC, Lacey MJ, Akhurst RJ, Gergson RP. Biologically active metabolites from Xenorhabdus sps. Part 2. Benzopyran-1-one derivatives with gastroprotective activity. J Nat Prod 54: 785-795 (1991)

4. Shimojima Y, Hayashi H, Ooka T, Shibukawa M. Studies on AI-77s, microbial products with pharmacological activities. Structure and the chemical nature of AI-77s. Tetrahedron 40: 2519-2527 (1984)

5. Zhang Y, Wu LJ, Tashiro S, Onodera S, Ikejima TE. Vodiamine induced tumor cell death through different pathways: apoptosis and necrosis. Acta Pharmacol Sin 25: 83-89 (2004) 